\title{
Date and Time of First Study Treatment
}

National Cancer Institute

\section{Source}

National Cancer Institute. Date and Time of First Study Treatment. NCI Thesaurus. Code C117455.

The date and time of the subject's first study treatment. 